\title{
A Novel Environmental Route to Ambient Pressure Dried Thermal Insulating Silica Aerogel via Recycled Coal Gangue
}

\author{
Pinghua Zhu, ${ }^{1}$ Meng Zheng, ${ }^{1}$ Shanyu Zhao, ${ }^{2}$ Junyong $W u,{ }^{1}$ and Haixun $X u^{1}$ \\ ${ }^{1}$ School of Environmental and Safety Engineering, Changzhou University, Changzhou, Jiangsu 213164, China \\ ${ }^{2}$ Swiss Federal Institute of Materials Science and Technology, 8600 Dübendorf, Switzerland \\ Correspondence should be addressed to Shanyu Zhao; syzhao65@gmail.com and Haixun Xu; haixunxu@gmail.com
}

Received 9 January 2016; Accepted 17 April 2016

Academic Editor: Patrice Berthod

Copyright (C) 2016 Pinghua Zhu et al. This is an open access article distributed under the Creative Commons Attribution License, which permits unrestricted use, distribution, and reproduction in any medium, provided the original work is properly cited.

\begin{abstract}
Coal gangue, one of the main hazardous emissions of purifying coal from coalmine industry, is rich in silica and alumina. However, the recycling of the waste is normally restricted by less efficient techniques and low attractive output; the utilization of such waste is still staying lower than $15 \%$. In this work, the silica aerogel materials were synthesized by using a precursor extracted from recycled silicon-rich coal gangue, followed by a single-step surface silylation and ambient pressure drying. A low density $\left(\sim 0.19 \mathrm{~g} / \mathrm{cm}^{3}\right)$ nanostructured aerogel with a 3D open porous microstructure and high surface area $\left(\sim 690 \mathrm{~m}^{2} / \mathrm{g}\right)$ was synthesized, which presents a superior thermal insulation performance $\left(\sim 26.5 \mathrm{~mW} \cdot \mathrm{m}^{-1} \cdot \mathrm{K}^{-1}\right.$ of a plane packed of $4-5 \mathrm{~mm}$ granules which was confirmed by transient hot-wire method). This study offers a new facile route to the synthesis of insulating aerogel material by recycling solid waste coal gangue and presents a potential cost reduction of industrial production of silica aerogels.
\end{abstract}

\section{Introduction}

Silica aerogel is one of the hot topics nowadays, because of its exceptional physical properties, for example, high porosity and specific surface area, low density, and thermal conductivity [1-6]. Amongst all attractive characteristics of the material, the most well-known feature is its superinsulating $\left(\lambda \leq 13 \mathrm{mWm}^{-1} \cdot \mathrm{K}^{-1}\right)$ at the Standard Temperature and Pressure (STP) condition and low flammability [3]. One of the state-of-the-art methods to prepare silica aerogel is solgel combined with ambient pressure drying. So far, organic silicon monomers, such as tetramethylorthosilicate (TMOS), tetraethyl orthosilicate (TEOS), and polyethoxydisiloxane (PEDS), are generally selected as precursors $[4,7,8]$ and the trimethylchlorosilane (TMCS) [9, 10], hexamethyldisiloxane (HMDSO) [11], and hexamethyldisilazane (HMDS) [7, 9, 12] were used for silylating silica gels, and aerogels were dried under ambient pressure conditions.

Coal gangue, a hazardous solid waste of purifying coal from coalmine industry, is rich in silica and alumina. But the recycling of such waste is normally restricted by less efficient techniques and low attractive outputs [13]. Nowadays, with an ever growing of coalmine industry, 3.8 billion tons' coal gangue was reported in 2014 in China with an increasing rate of 0.2 billion tons per year; it has been recognized as one of the main hazardous industrial emissions [14]. Many efforts have been made to develop facile and effective routes to extend the coal gangue applications; however, the utilization of such waste is still staying lower than $15 \%$ [15], and the main applications are limited in typical building materials, for example, concrete filling materials and composite cements [16]; therefore, the overall development of the coal gangue is narrow, and the efficient approach and potential application field studies are of great importance for the resource recovery of waste coal gangue.

Since it is rich in silicon, coal gangue could be used as a cheap silicon raw material. Few literatures have been reported on the relatively pure activated silica and its applications in aerogel materials. Dong et al. [17] extracted the high purity silica aerogel from coal gangue by acid leaching with a yield of $68.04 \%$. Hou et al. [18] have investigated the optimal temperature $\left(700^{\circ} \mathrm{C}\right)$ and time (2 hours) for extracting potential available silicon (around $17.65 \mathrm{wt} . \%$ ). Zhu et al. [19] reported the synthesis of silica xerogels from coal 
TABLE 1: Elemental analysis of the raw coal gangue (wt.\%).

\begin{tabular}{ccccccccccccc}
\hline $\mathrm{SiO}_{2}$ & $\mathrm{Al}_{2} \mathrm{O}_{3}$ & $\mathrm{CaO}$ & $\mathrm{Fe}_{2} \mathrm{O}_{3}$ & $\mathrm{TiO}_{2}$ & $\mathrm{SO}_{3}$ & $\mathrm{~K}_{2} \mathrm{O}$ & $\mathrm{MgO}$ & $\mathrm{P}_{2} \mathrm{O}_{5}$ & $\mathrm{MnO}$ & $\mathrm{V}_{2} \mathrm{O}_{5}$ & $\sigma^{\mathrm{a}}$ & $\mathrm{Total}$ \\
\hline 43.59 & 12.05 & 10.95 & 9.01 & 0.50 & 19.29 & 2.31 & 0.61 & 0.84 & 0.05 & 0.10 & \pm 0.03 & 100 \\
\hline${ }^{\mathrm{a}} \mathrm{Stan}$
\end{tabular}

${ }^{\mathrm{a}}$ Standard deviation.

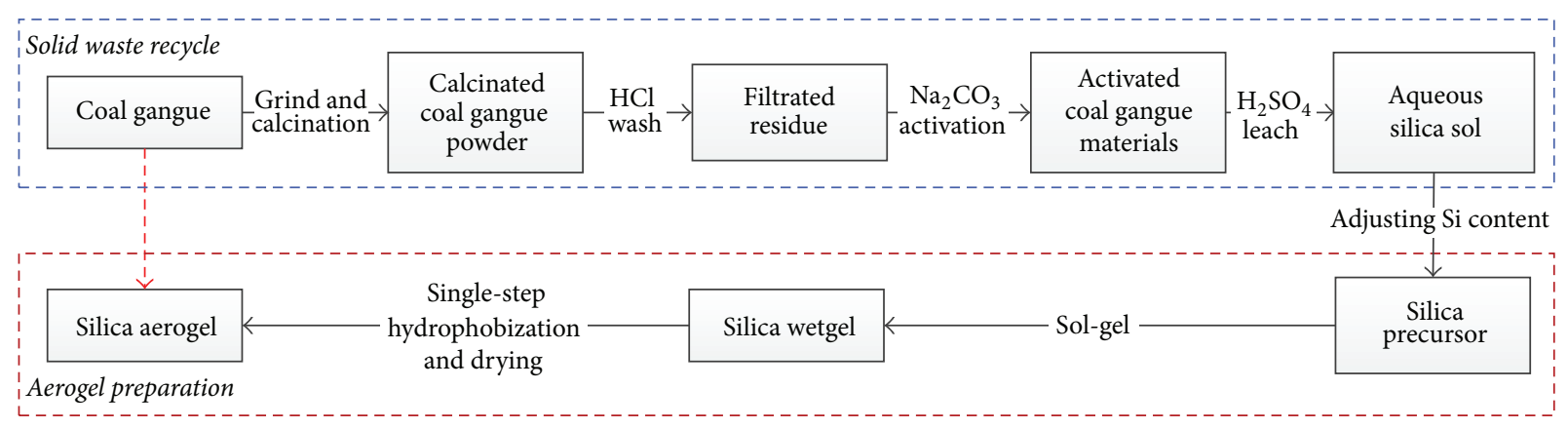

FIGURE 1: Schematic presentation of the main steps of silica aerogel preparation from coal gangue.

gangue by ambient drying of trimethylchlorosilane modified gels; the $88.97 \%$ porosity and $0.256 \mathrm{~g} / \mathrm{cm}^{3}$ density were achieved, but there is no report on the extraction yield and thermal performance of the xerogels. Overall, there are few reports on silica xerogel preparation from coal gangue, the reported utilization of the silicon resource was lower than $70 \%$, and no systematical characterizations of such materials, but quite a lot of publications, were reported for precipitated silica fabrications [20-22]; however, the main challenge of aerogel preparation is controlling high $\mathrm{SiO}_{2} / \mathrm{Na}_{2} \mathrm{O}$ molar ratio in the extracted silicon sol (over $1: 1$, which needs to restrict $\mathrm{Na}^{+}$loading or increase silicon concentration) [23] and high extraction efficiency of silica (which requires high $\mathrm{Na}^{+}$concentration and large amount of solvent) and low concentration of impurities, such as $\mathrm{Al}, \mathrm{Fe}$, and $\mathrm{Mg}$, in the final gels (which affects the transparence and thermal performance of aerogels). In this case, if we can efficiently wash the impurities out, extract silica, and adjust the $\mathrm{SiO}_{2} / \mathrm{Na}_{2} \mathrm{O}$ ratio, this will concomitantly ameliorate both the silicon extraction efficiency and final aerogel performances. It has been motivated to develop a feasible route for such high performance materials preparation, that is, silica aerogels and its corresponding composite materials with a great potential of recycle use of low cost and environmental correlated large stocked solid waste.

In this work, waste coal gangue was used as the rich silicon raw material for the preparation of silica aerogel by using a " 3 -step extraction" route to extract and purify $\mathrm{SiO}_{2}$ from coal gangue, adjusting $\mathrm{SiO}_{2}$ concentration, promoting sol-gel transition, and following single-step solvent exchange/hydrophobization/ambient drying; over $96 \%$ silicon was extracted as the silica precursor; lightweight $(\sim$ $0.19 \mathrm{~g} / \mathrm{cm}^{3}$ ) and nanostructured granular aerogel materials were synthesized by this route (Figure 1), which shows a decent thermal conductance $(\lambda)$ of $26.5 \times 10^{-3} \mathrm{~W} \cdot \mathrm{m}^{-1} \mathrm{~K}^{-1}$ of 4-5 mm packed granules. The study offers a feasible route for synthesizing silica aerogel from recycled waste coal gangue and presents potential niche markets established from such novel route synthesized aerogels.

\section{Experimental}

2.1. Chemicals. Hydrochloric acid ( $\mathrm{HCl}, 37 \%)$, sulfuric acid $\left(\mathrm{H}_{2} \mathrm{SO}_{4}, 98 \%\right)$, and sodium carbonate $\left(\mathrm{Na}_{2} \mathrm{CO}_{3},>99.8 \%\right)$ were purchased from Cancheng Chemical Co., Ltd., China; ammonium hydroxide solution $\left(\mathrm{NH}_{3} \cdot \mathrm{H}_{2} \mathrm{O}, 28-30 \%\right)$ was obtained from Shanghai Lingche Chemical Co., Ltd., China. Chlorotrimethylsilane (TMCS, 99\%, Sigma-Aldrich Co.) was used for the hydrophobization treatment of the aerogels. Ethanol (ACS > 99.8\%, Fluka) and heptane (98\%, Fluka) were used as the organic solvents. Deionized water was homemade and used in all experiments. All chemicals were used as received without any further purification.

\subsection{Silicon Precursor Preparation}

2.2.1. Sources of Raw Coal Gangue. Raw coal gangue was provided by Jintan Coal Mining Co., Ltd., Changzhou, China. The raw materials were crushed by a hammer crusher (PZC180X150, Aolian Technology Co., Ltd., Changzhou, China) and passed through a $0.3 \mathrm{~mm}$ sieve. As-received coal gangue contains less than $15 \mathrm{wt} . \% \mathrm{C}$; the elemental and mineral analysis were measured by X-ray fluorescence (XRF) spectrometer and Powder X-ray diffraction (XRD), as shown in Table 1 and Figure 2, respectively. The main crystalline components of the coal gangue could be identified in Figure 2 as illite $\left(\mathrm{X}_{2} \mathrm{Y}_{4-6} \mathrm{Z}_{8} \mathrm{O}_{20}(\mathrm{OH}, \mathrm{F})_{4}: \mathrm{X}\right.$ is $\mathrm{K}$ and $\mathrm{Ca}, \mathrm{Y}$ is $\mathrm{Al}, \mathrm{Mg}$, and $\mathrm{Fe}$, and $\mathrm{Z}$ is $\mathrm{Si}$ or $\mathrm{Al})$, kaolinite $\left(\mathrm{Al}_{2} \mathrm{Si}_{2} \mathrm{O}_{5}(\mathrm{OH})_{4}\right)$, siderite $\left(\mathrm{FeCO}_{3}\right)$, and quartz $\left(\mathrm{SiO}_{2}\right)$ and so forth, which are consistent with the literature [24], but the specific peaks of siderite and illite are relatively weak and mostly overlapped by the peaks of kaolinite and quartz, which are confirmed as the main components of this coal gangue. 


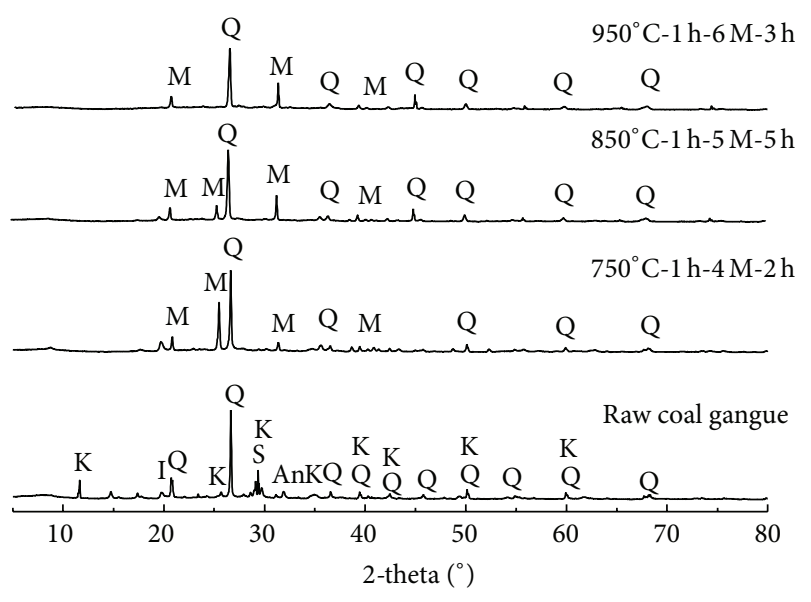

$\begin{array}{ll}\text { Q: quartz } & \text { M: mullite } \\ \text { K: kaolinite } & \text { Ch: chlorite } \\ \text { I: illite } & \text { S: siderite }\end{array}$

An: ankerite

FIgURE 2: X-ray diffraction of the raw coal gangue and coal gangue after acid leach and typical chemical formula of the mineral components: quartz $\left(\mathrm{SiO}_{2}\right)$, illite $\left(\mathrm{KAl}_{2}\left[\left(\mathrm{Al}, \mathrm{Si}_{)} \mathrm{Si}_{3} \mathrm{O}_{10}\right]\right)\right.$, kaolinite $\left(\mathrm{Al}_{2} \mathrm{Si}_{2} \mathrm{O}_{5}(\mathrm{OH})_{4}\right)$, ankerite $\left(\mathrm{CaMg}\left(\mathrm{CO}_{3}\right)_{2}\right)$, mullite (Al6Si2O13), and siderite $\left(\mathrm{FeCO}_{3}\right)$.

2.2.2. Extraction of $\mathrm{SiO}_{2}$ from Coal Gangue. Around 44 wt.\% $\mathrm{SiO}_{2}$ in the raw coal gangue is shown in Table 1 , which is the target material to be extracted out for using as precursor of silica aerogel preparation.

A 3-step protocol was designed by considering an efficient separation of silicon out of raw coal gangue material, as follows:

(i) leaching out impurities, that is, $\mathrm{Fe}^{2+}, \mathrm{Al}^{3+}$ (partially), $\mathrm{K}^{+}, \mathrm{SO}_{3}$, and so forth, by treating the coal gangue in a muffle furnace (SX2-2.5-12, Shanghai Hede Instrument Co., Ltd., China) and fast cooling it down in a cool water to activate the raw materials by introducing crystalline defects and keeping reactive amorphous structures: the impurity ions, for example, $\mathrm{Al}^{3+}$ and $\mathrm{Fe}^{3+}$, could be extracted for industrial use as well $[17,25]$, which is not the main topic and will not be discussed in this paper. The optimized calcination process is $850^{\circ} \mathrm{C}$ which was determined by thermogravimetric analysis (TGA) and differential scanning calorimetry (DSC) [24]. After calcination, the coal gangue was leached by $5 \mathrm{~mol} / \mathrm{L} \mathrm{HCl}$ solution for 5 hours [24],

(ii) transferring stable silicon-rich components, such as kaolinite and quartz, to easily soluble compounds, for example, albite and nephelite: in order to improve the $\mathrm{SiO}_{2}$ extraction efficiency [24], as-treated coal gangue materials were mixed with $\mathrm{Na}_{2} \mathrm{CO}_{3}$ in the respect mass ratio of $0.8,0.9,1.0,1.2,1.3,1.4,1.5$, and 1.6 and calcinated at $750^{\circ} \mathrm{C}, 800^{\circ} \mathrm{C}, 850^{\circ} \mathrm{C}$, and $900^{\circ} \mathrm{C}$ for 1,2 , 3,4 , and 5 hours,

(iii) extracting silicon by using relative high concentration $\mathrm{H}_{2} \mathrm{SO}_{4}$ solution: the activated coal gangue was dispersed into $4 \mathrm{~mol} / \mathrm{L} \mathrm{H}_{2} \mathrm{SO}_{4}$ solutions at room temperature and the solid-liquid weight ratio was kept as $1: 10$.

\section{3. $\mathrm{SiO}_{2}$ Aerogel Synthesis}

2.3.1. $\mathrm{SiO}_{2}$ Wetgel Preparation. As-prepared silica sols with certain silicon concentration were used directly as aerogel precursor. The resulting aqueous silica sol has a $\mathrm{pH}$ of 0.5 , the sol is getting viscous after the addition of sulfuric acid, the gelation time depends on the concentration of $\mathrm{H}_{2} \mathrm{SO}_{4}$, and the gelation occurred about 10 minutes when $4 \mathrm{M} \mathrm{H}_{2} \mathrm{SO}_{4}$ was added.

2.3.2. Surface Modification and Ambient Drying. After gelation, the gel was washed 3 times in the diluted $1 \mathrm{M} \mathrm{H}_{2} \mathrm{SO}_{4}$ solution at $55^{\circ} \mathrm{C}$ for $24 \mathrm{hrs}$. After aging, hydrophobization of the gel surfaces (chemical modification with trimethylsilyl (TMS) groups) was carried out by soaking the gels in a heptane/ethanol/TMCS solution with a molar ratio of $15: 1: 1$ at $65^{\circ} \mathrm{C}$ for $24 \mathrm{hrs}$. The gels were then dried in a convective oven at $120^{\circ} \mathrm{C}$ for 2 hours.

\subsection{Characterization}

Mineral and Elemental Analysis. X-ray diffraction (XRD) analysis was recorded on APEX II DUO X-ray system (Rigaku Corporation, Japan) equipped with a $\mathrm{Cu} \mathrm{K} \alpha$ source at $40 \mathrm{~mA}$ and $40 \mathrm{kV}$. The data were collected from a 2-theta degree in the range of $10^{\circ}$ to $80^{\circ}$ at a step of $6^{\circ} / \mathrm{min}$. DTA and DSC were performed on a thermos-gravimetric analyzer (TGA92, SETARAM, France) in the air atmosphere. $10 \mathrm{mg}$ sample was performed with the heating rate of $10^{\circ} \mathrm{C} / \mathrm{min}$. X-ray fluorescence (XRF) spectrometer was analyzed on EA2400II system (PerkinElmer, USA) at $50 \mathrm{kV}$ and $40 \mathrm{~mA}$.

Scanning Electron Microscope (SEM) Characterization. Silica aerogel materials were analyzed by coating them with a $10 \mathrm{~nm}$ thick platinum layer. SEM analysis of all materials was performed on FEI Nova NanoSEM 230 instrument (FEI, Hillsboro, Oregon, USA) at an accelerating voltage of $10 \mathrm{kV}$ and a working distance of $5 \mathrm{~mm}$.

Transmittance Electron Microscope (TEM) Characterization. The microstructure of the aerogel was recorded on a transmission electron microscopy (Philips-EM 420) operated at an accelerating voltage of $200 \mathrm{kV}$.

Thermal Conductivity. The thermal conductivity was measured on an in-house built transient hot-wire device at $25^{\circ} \mathrm{C}$ and $50 \%$ relative humidity $(\mathrm{RH})$ [24]. The corresponding results were analyzed by the method published by Karaipekli et al. [26]. The $\mathrm{Cu} / \mathrm{Ni}$ alloy wire was chosen as $73 \mathrm{~mm}$ in length and $0.127 \mathrm{~mm}$ in diameter to obtain the optimum ratio of 575 [27]. The transient lambda was calculated by

$$
\lambda=\frac{V I / 4 \pi L}{d T / d(\ln t)},
$$


TABLE 2: Acid leach experiment of the coal gangue.

\begin{tabular}{|c|c|c|c|c|c|}
\hline Sample & $\begin{array}{c}\text { Calcination } \\
\text { temperature }\left({ }^{\circ} \mathrm{C}\right)\end{array}$ & Calcination time $(\mathrm{h})$ & $\begin{array}{c}\mathrm{HCl} \text { concentration } \\
(\mathrm{mol} / \mathrm{L})\end{array}$ & $\begin{array}{l}\text { Reaction period } \\
\text { (h) }\end{array}$ & Silicon concentration in the residue (\%) \\
\hline CSi-1 & 750 & 1 & 4 & 2 & $72.84 \pm 1.50$ \\
\hline $\mathrm{CSi}-2$ & 750 & 2 & 5 & 3 & $79.06 \pm 1.13$ \\
\hline $\mathrm{CSi}-3$ & 750 & 4 & 6 & 5 & $79.10 \pm 2.55$ \\
\hline $\mathrm{CSi}-4$ & 850 & 1 & 5 & 5 & $79.03 \pm 0.81$ \\
\hline CSi-5 & 850 & 2 & 6 & 2 & $78.37 \pm 3.10$ \\
\hline CSi-6 & 850 & 4 & 4 & 3 & $75.45 \pm 1.72$ \\
\hline $\mathrm{CSi}-7$ & 950 & 1 & 6 & 3 & $68.88 \pm 2.31$ \\
\hline CSi-8 & 950 & 2 & 4 & 5 & $74.43 \pm 1.55$ \\
\hline CSi-9 & 950 & 4 & 5 & 2 & $68.69 \pm 2.10$ \\
\hline
\end{tabular}

where $V$ and $I$ are the voltage and current, whose fixed values are $1 \mathrm{~V}$ and $0.23 \mathrm{~A}$ in this experiment, $L$ is the length of CuNi alloy wire $\left(73 \mathrm{~mm}, 0.15 \Omega \mathrm{mm}^{2} / \mathrm{m}\right)$, and $d T / d(\ln t)$ is the average fitting slope of the measurements.

Evaluation of Density and Porosity. The bulk density was determined from the envelope volume, which is recorded on GeoPyc 1360, Micromeritics, US, and the skeletal density is measured on AccuPyc 1340, Micromeritics, US. The porosity of the aerogels $(\varepsilon \%)$ was calculated using the following:

$$
\varepsilon \%=\left(1-\frac{\rho_{\text {bulk }}}{\rho_{\text {skeleton }}}\right) \times 100,
$$

where $\rho_{\text {bulk }}$ and $\rho_{\text {skeleton }}$ are the volumetric mass densities of aerogel and skeletal density of silica, respectively.

Evaluation of the Brunauer-Emmett-Teller (BET) Specific Surface Area. Nitrogen adsorption and desorption isotherms at $-196^{\circ} \mathrm{C}$ were obtained on Micromeritics ASAP 2020a instrument. The specific surface area of the samples was determined by the Brunauer-Emmett-Teller (BET) method. The pore size distribution was obtained from the desorption branch of the isotherm using the Barrett-Joyner-Halender $(\mathrm{BJH})$ model. The pore volume $\left(V_{\text {pore }}\right)$ and average pore diameter $\left(D_{\text {pore }}\right)$ were calculated from the density of the aerogel and its specific surface area using the following:

$$
\begin{aligned}
& V_{\text {pore }}=\frac{1}{\rho}-\frac{1}{\rho_{\text {skeleton }}}, \\
& D_{\text {pore }}=\frac{4 V_{\text {pore }}}{S_{\text {BET }}},
\end{aligned}
$$

where $\rho$ is the density of the aerogel, $\rho_{\text {skeleton }}$ is the density of aerogel skeleton, and $S_{\mathrm{BET}}$ is the specific surface area as measured using BET.

\section{Results and Discussion}

3.1. Removal of the Soluble $\mathrm{Fe}^{3+}$ and $\mathrm{Al}^{3+}$ Impurities. In order to extract relative pure silica out of coal gangue for fabricating aerogel materials, a calcination and $\mathrm{HCl}$ leaching

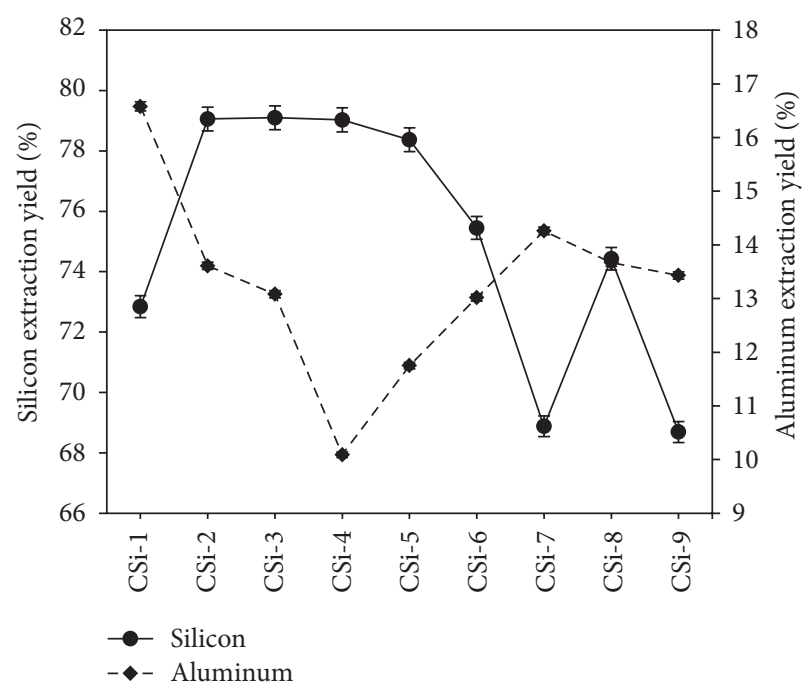

FIgure 3: The concentration of silicon and aluminum after $\mathrm{HCl}$ leach.

process was designed to remove most of soluble impurities (namely, some $\mathrm{Fe}^{3+}$ and $\mathrm{Al}^{3+}$ compounds and $\mathrm{K}^{+}$and $\mathrm{P}^{5+}$ oxides), listed in Table 2. After heat treating and $\mathrm{HCl}$ leaching, most of the quartz phase remained, the peaks assigned to kaolinite were no longer distinguished anymore, as shown in Figure 2, which correlates with a degradation of $\mathrm{Al} / \mathrm{Si}$ compounds, the peaks belonging to iron mineral of siderite were getting weaker, especially at $750^{\circ} \mathrm{C}$ and $850^{\circ} \mathrm{C}$ treatments, which indicates an effective removal of $\mathrm{Fe}$ and $\mathrm{Al}$ compounds from the coal gangue, and most of the silicon phases were still retained. After acid leaching, most samples show relatively high silicon contents over $74 \mathrm{wt} . \%$; according to Figure 3, the most attractive protocol is that the coal gangue was treated at $850^{\circ} \mathrm{C}$ for 2 hours and then leached by $5 \mathrm{~mol} / \mathrm{L} \mathrm{HCl}$ solution for 5 hours; the sample CSi- 4 keeps relatively high concentration of silicon and removes most of aluminum.

3.2. Chemical Activation of Coal Gangue with an Addition of $\mathrm{Na}_{2} \mathrm{CO}_{3}$. The most promising coal gangue intermediate CSi-4 was further activated by the addition of $\mathrm{Na}_{2} \mathrm{CO}_{3}$; 
TABLE 3: Extraction of $\mathrm{SiO}_{2}$ after chemical activation.

\begin{tabular}{|c|c|c|c|c|c|}
\hline Samples & $\begin{array}{c}\mathrm{Na}_{2} \mathrm{CO}_{3} \text { coal gangue } \\
(\mathrm{w} / \mathrm{w})\end{array}$ & $\begin{array}{c}\text { Calcination } \\
\text { temperature }\left({ }^{\circ} \mathrm{C}\right)\end{array}$ & $\begin{array}{l}\text { Calcination time } \\
\text { (hours) }\end{array}$ & Silicon yield (\%) & $\mathrm{Si} / \mathrm{Na} \mathrm{mol} / \mathrm{mol}$ \\
\hline CSi-4-1 & 0.8 & 850 & 2 & $96.49 \pm 1.31$ & $1: 1$ \\
\hline CSi- $4-2$ & 0.9 & 850 & 2 & $96.47 \pm 1.52$ & $0.88: 1$ \\
\hline $\mathrm{CSi}-4-3$ & 1.0 & 750 & 2 & $76.70 \pm 1.23$ & $0.62: 1$ \\
\hline $\mathrm{CSi}-4-4$ & 1.0 & 800 & 2 & $95.58 \pm 1.69$ & $0.77: 1$ \\
\hline CSi-4-5 & 1.0 & 850 & 2 & $98.70 \pm 0.56$ & $0.80: 1$ \\
\hline CSi-4-6 & 1.0 & 900 & 2 & $89.02 \pm 2.52$ & $0.72: 1$ \\
\hline CSi-4-7 & 1.2 & 850 & 1 & $95.18 \pm 3.05$ & $0.64: 1$ \\
\hline CSi-4-8 & 1.2 & 850 & 2 & $99.50 \pm 2.59$ & $0.66: 1$ \\
\hline CSi-4-9 & 1.2 & 850 & 3 & $98.53 \pm 1.52$ & $0.66: 1$ \\
\hline CSi-4-10 & 1.2 & 850 & 4 & $93.64 \pm 0.53$ & $0.63: 1$ \\
\hline CSi-4-11 & 1.2 & 850 & 5 & $90.76 \pm 0.86$ & $0.61: 1$ \\
\hline CSi-4-12 & 1.3 & 850 & 2 & $98.70 \pm 1.79$ & $0.61: 1$ \\
\hline CSi-4-13 & 1.4 & 850 & 2 & $99.20 \pm 0.92$ & $0.57: 1$ \\
\hline CSi-4-14 & 1.5 & 850 & 2 & $97.28 \pm 1.63$ & $0.52: 1$ \\
\hline CSi-4-15 & 1.6 & 850 & 2 & $98.46 \pm 2.46$ & $0.50: 1$ \\
\hline
\end{tabular}

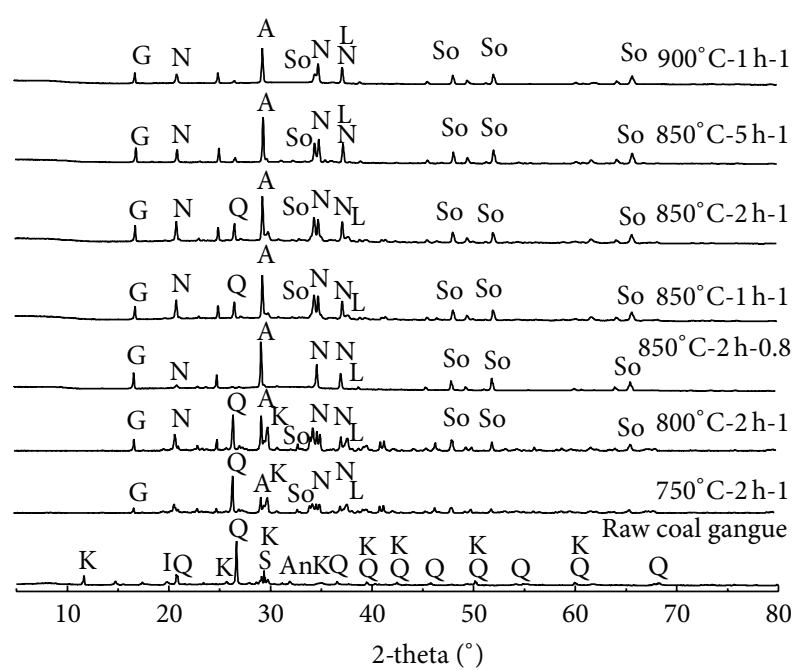

$\begin{array}{ll}\text { Q: quartz } & \text { So: sodium silicate } \\ \text { K: kaolinite } & \text { I: illite } \\ \text { A: albite } & \text { An: ankerite } \\ \text { N: nepheline } & \text { S: siderite } \\ \text { L: lime } & \text { G: gismondine }\end{array}$

FIGURE 4: X-ray diffraction of coal gangue after $\mathrm{Na}_{2} \mathrm{CO}_{3}$ activation and $\mathrm{H}_{2} \mathrm{SO}_{4}$ wash and typical chemical formula of the mineral components: quartz $\left(\mathrm{SiO}_{2}\right)$, kaolinite $\left(\mathrm{Al}_{2} \mathrm{Si}_{2} \mathrm{O}_{5}(\mathrm{OH})_{4}\right)$, albite $\left(\mathrm{NaAlSi}_{3} \mathrm{O}_{8}\right)$, nepheline $\left(\mathrm{KNa}_{3}\left(\mathrm{AlSiO}_{4}\right)_{4}\right)$, lime $(\mathrm{CaO})$, sodium silicate $\left(\mathrm{Na}_{2} \mathrm{O} \cdot n \mathrm{SiO}_{2}\right)$, illite $\left(\mathrm{KAl}_{2}\left[(\mathrm{Al}, \mathrm{Si}) \mathrm{Si}_{3} \mathrm{O}_{10}\right]\right)$, ankerite $\left(\mathrm{CaMg}\left(\mathrm{CO}_{3}\right)_{2}\right)$, siderite $\left(\mathrm{FeCO}_{3}\right)$, and gismondine $\left(\mathrm{Ca}\left(\mathrm{Al}_{2} \mathrm{Si}_{3} \mathrm{O}_{10}\right)\right.$. $\left.3 \mathrm{H}_{2} \mathrm{O}\right)$.

most of the Kaolinite $\left(\mathrm{Al}_{2} \mathrm{Si}_{2} \mathrm{O}_{5}(\mathrm{OH})_{4}\right)$ and Quartz $\left(\mathrm{SiO}_{2}\right)$ can be transferred to albite $\left(\mathrm{NaAlSi}_{3} \mathrm{O}_{8}\right)$ and nepheline $\left(\mathrm{Na}_{3} \mathrm{KAl}_{4} \mathrm{Si}_{4} \mathrm{O}_{16}\right)$ phase or analogs, as shown in Figure 4, which could be dissolved in an aqueous acidic solution. The activation details were listed in Table 3, further extraction was carried out by dissolving coal gangue solid in a $4 \mathrm{~mol} / \mathrm{L}$ sulfuric acid solution, and the solid/acid solution mass ratio was kept consistent $(1: 10)$ for all samples. It was found that the $\mathrm{SiO}_{2}$ extraction is improved by the increase of calcination temperature, the highest extraction of $99.5 \%$ was reached at $850^{\circ} \mathrm{C}$, and further increase of temperature to $900^{\circ} \mathrm{C}$ leads to a significant drop of the leaching out of $\mathrm{SiO}_{2}$ (Figure 5(a)), which may be induced by densifying the coal gangue under relevant high calcination temperature. Then, $850^{\circ} \mathrm{C}$ was used to evaluate the amounts of $\mathrm{Na}_{2} \mathrm{CO}_{3}$, the mass ratio of $\mathrm{Na}_{2} \mathrm{CO}_{3}$ to coal gangue was adjusted from 0.6 to 1.6 , a significant improvement of the extraction of $\mathrm{SiO}_{2}$ was observed at the ratio range of $0.6-0.8$, which correlates with an increase from $45 \%$ to $95 \%$, and there is no significant improvement after 0.8 (Figure 5(b)). And the calcination time was varied from 1 to 5 hours at $850^{\circ} \mathrm{C}$, the optimal heating period was identified at 2 hours, and longer calcination brings the leaching efficiency down (Figure 5(c)). Furthermore, the Na/Si molar ratio was calculated from the $\mathrm{Na}_{2} \mathrm{CO}_{3}$ /coal gangue ratio and silicon extraction yield and listed in Table 3; the high $\mathrm{Na}_{2} \mathrm{CO}_{3}$ to coal gangue ratio leads to an increase of $\mathrm{Na} / \mathrm{Si}$ molar ratio in the extracted sodium silicate sol, which is prone to precipitate during sol-gel transition [24]. Overall, the optimized condition for chemically activating coal gangue is the mass ratio of $\mathrm{Na}_{2} \mathrm{CO}_{3}$ : coal gangue $=0.8$ and is calcinated at $850^{\circ} \mathrm{C}$ for 2 hours (CSi-4-1), which leads to the highest $\mathrm{Si} / \mathrm{Na}$ molar ratio of $1: 1$.

3.3. Microstructure of Silica Aerogels Derived from Coal Gangue Extracted $\mathrm{SiO}_{2}$. A light weight $\left(\rho_{\text {bulk }}=0.19 \mathrm{~g} \mathrm{~cm}^{-3}\right)$, high porosity $\left(\varepsilon=91.4 \%\right.$ ) $\mathrm{SiO}_{2}$ aerogel material (CSi-4-1) was obtained by using the coal gangue derived silicon precursor (physical properties were listed in Table 4), and a typical mesoporous structure of such material was identified under 


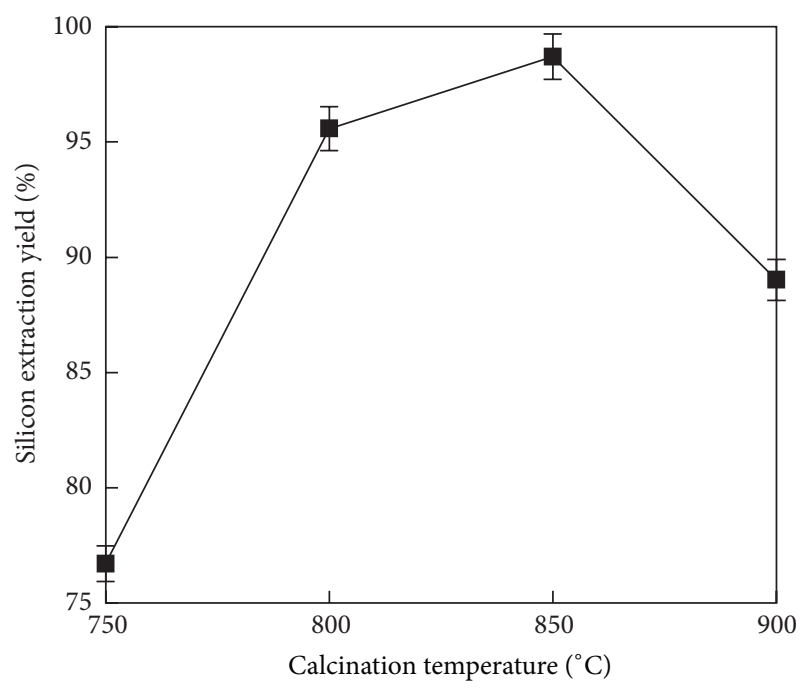

(a)

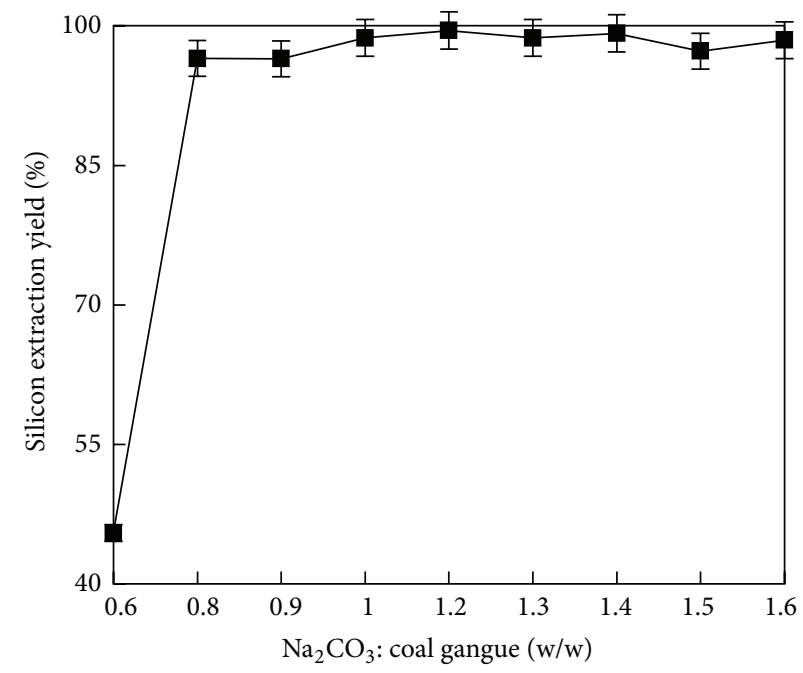

(b)

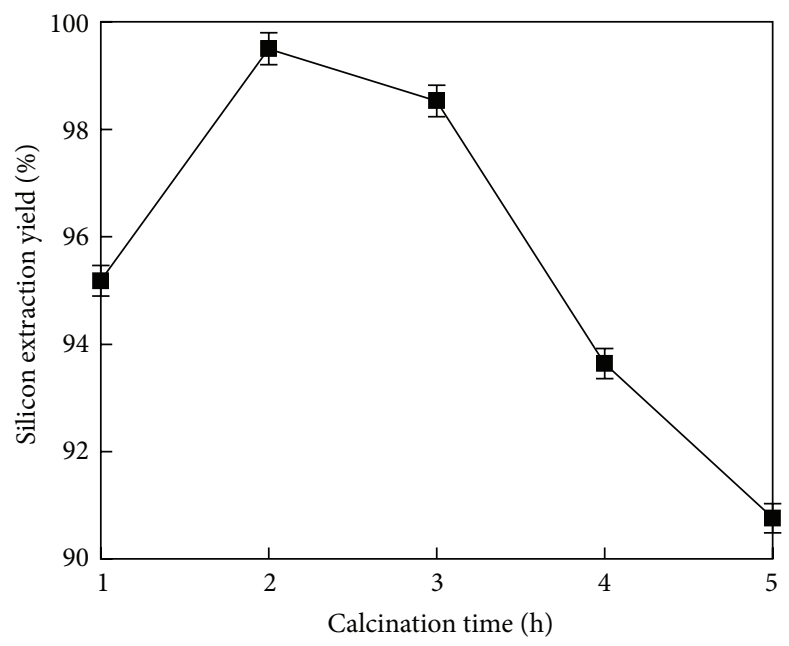

(c)

FIGURE 5: The silicon extraction yields adjusted by (a) the calcination temperature, (b) the $\mathrm{Na}_{2} \mathrm{CO}_{3}$ to coal gangue ratio, and (c) calcination time.

SEM (Figure 6). Homogenously distributed silica building blocks (around 20-50 $\mathrm{nm}$ ) were assembled to form a threedimensional network with the pores ranging from several $\mathrm{nm}$ to over $100 \mathrm{~nm}$.

A detailed examination of the aerogel materials under TEM (Figure 7) verifies a hierarchical porous structure with a typical pearl necklace structure with most of the primary colloidal particles in a range of 5-8 $\mathrm{nm}$ and $1-2 \mathrm{~nm}$ interparticle pores, which is in agreement with the reported typical waterglass-based silica aerogel structures [28]. The hierarchical structure of the aerogel materials observed from the microscopic analysis is mainly attributed to the different size of "building blocks" of the gel particles; the TEM shows around $5 \mathrm{~nm}$ primary $\mathrm{SiO}_{2}$ particles; the primary particles were agglomerated to build the secondary clusters and shown as the blackberry structure in the SEM images. The varied sizes of the particles and pores lead to a superporous light
TABLE 4: Physical properties of the silica aerogel.

\begin{tabular}{lc}
\hline$\rho_{\text {bulk }}\left(\mathrm{g} \mathrm{cm}^{-3}\right)$ & $0.19 \pm 0.05$ \\
$\rho_{\text {skeleton }}\left(\mathrm{g} \mathrm{cm}^{-3}\right)$ & $2.21 \pm 0.02$ \\
$\varepsilon \%$ & $91.4 \%$ \\
$S_{\text {BET }}\left(\mathrm{m}^{2} \mathrm{~g}^{-1}\right)$ & 690 \\
$V_{\text {pore }}\left(\mathrm{cm}^{3} \mathrm{~g}^{-1}\right)$ & 4.81 \\
$D_{\text {pore }}(\mathrm{nm})$ & 27.5 \\
\hline
\end{tabular}

gel structure (Table 4) and show a successful preparation of aerogel materials from the coal gangue raw material.

The $\mathrm{N}_{2}$ adsorption-desorption isotherms and relevant pore size distribution of the aerogel prepared from CSi-41 are shown in Figure 8. The BET measurement could be influenced equilibrium intervals of the gas adsorption [28]. 


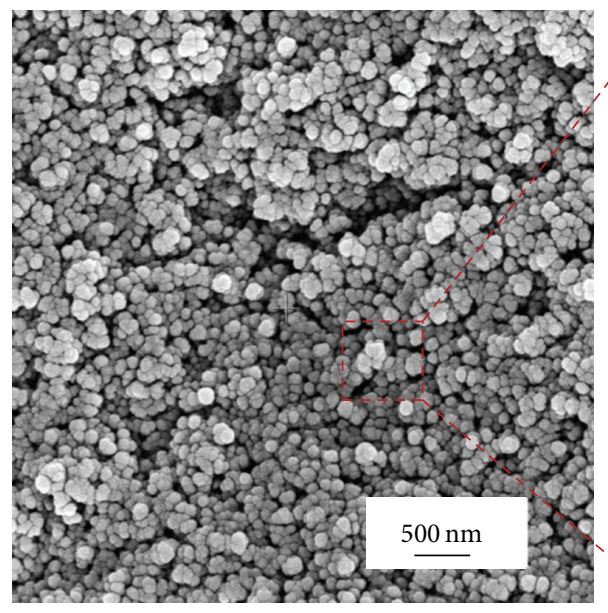

(a)



(b)

FIGURE 6: SEM images of aerogel materials derived from CSi-4-1 at (a) 50,000x and (b) 400,000x magnifications.

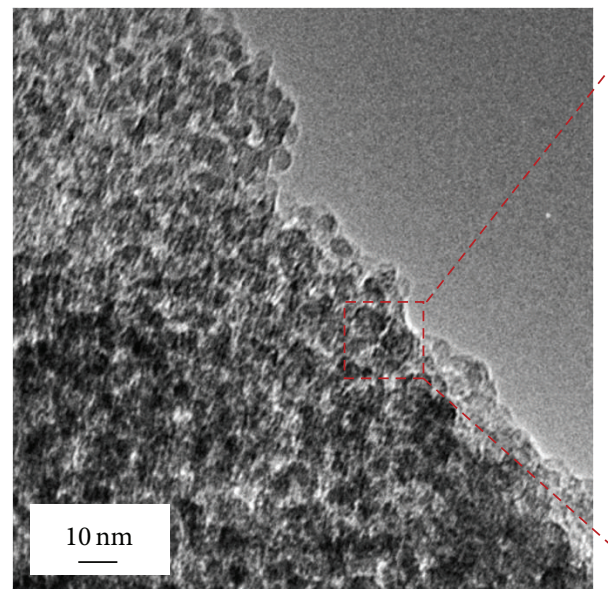

(a)

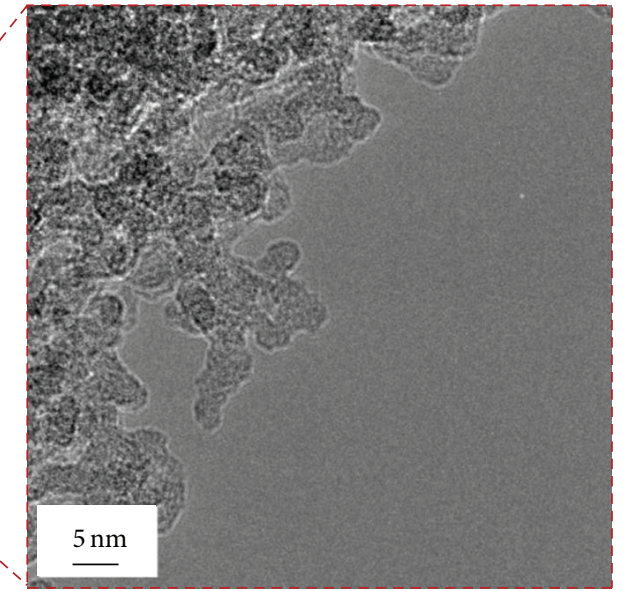

(b)

FIgURE 7: TEM images of aerogel materials.

Therefore, in this paper, we tried to repeat the measurements twice with different equilibration times, and the deviations of the main parameters (e.g., surface area, pore size, and pore volume) were around 5\%. The isotherm of such aerogel material is close to type 4 . The majority of the uptake takes place between relative pressures of 0.1 and 0.95 , and the pore volume $V_{\text {pore }}=4.81 \mathrm{~cm}^{3} \mathrm{~g}^{-1}$ and pore size $D_{\text {pore }}=27.5 \mathrm{~nm}$ were calculated from density and surface area, as shown in Table 4, in agreement with the microscopic analysis of Figures 6 and 7, in which the majority of species of mesopores (2$50 \mathrm{~nm}$ ) were observed.

The Barret-Joyner-Halenda (BJH) equilibrium model was applied for pore size analysis. The pore size distribution (PSD) analysis of silica aerogel shows a minority of micropores $(\sim$ $15-25 \mathrm{~nm}$ ) and a small amount of macropores (from $50 \mathrm{~nm}$ all the way up to $55 \mathrm{~nm}$ ) were identified. The $\mathrm{BJH}$ pore size analysis is mostly valid for the pore size in the range of $~$ 1 to $150 \mathrm{~nm}$ (mesopores and part of macroporous regime); therefore, some of the big pores built by the secondary clusters (shown in SEM, Figure 6) are not detectable. But the pore size and surface area of the coal gangue derived aerogel are comparable to the typical aerogels prepared from TEOS and waterglass [28]; in this case, it could be assumed that the large macropores are the minority species and indicate that the aerogel materials prepared from coal gangue present similar structures as typical silica aerogel [29] and should display identical performance, that is, thermal insulation, to such material.

3.4. Thermal Conductivity of Coal Gangue Derived Silica Aerogels. Thermal insulation is one of the main applications of aerogel-like materials. Ambient thermal conductivity of the granular coal gangue derived aerogel was measured on a packed $1 \times 1 \times 10 \mathrm{~cm}^{3}$ granule filled frame by transient hot-wire method [24]; a thermal conductivity of $26.5 \times$ 


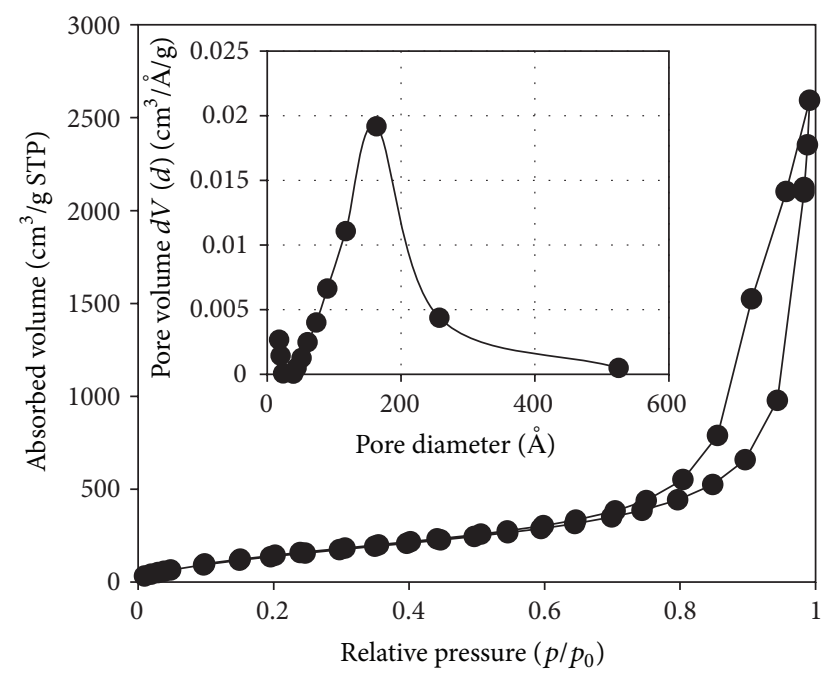

Figure 8: $\mathrm{N}_{2}$ adsorption-desorption (BET isotherm) and $\mathrm{BJH}$ pore size distribution (inset, derived from absorption branch) of the aerogel materials.

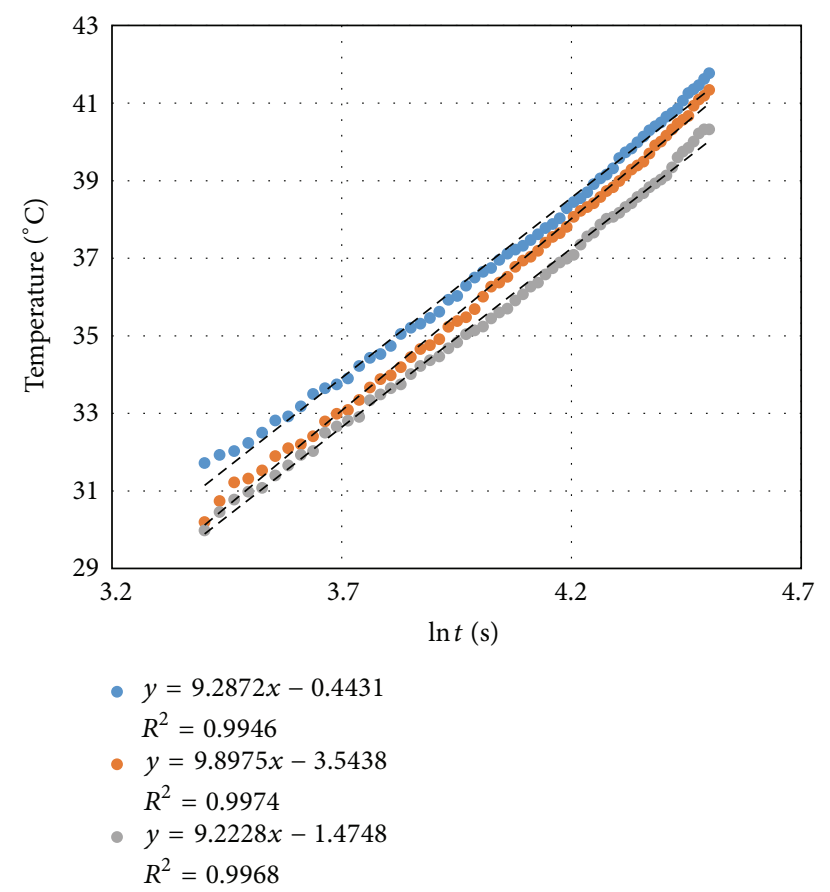

FIGURE 9: Evaluation of thermal conductivities of aerogel material by transient hot-wire method.

$10^{-3} \mathrm{~W} \mathrm{~m}^{-1} \mathrm{~K}^{-1}$ was calculated from (1) by using the slopes of Figure 9. The in-house measurement device was calibrated by the standard material (Expanded Polystyrene Board) with known thermal conductivity and measurements were repeated 3 times with the deviation of 3.9\%. A slight higher value (typical silica aerogel thermal conductance of $12-$ $18 \times 10^{-3} \mathrm{~W} \mathrm{~m}^{-1} \mathrm{~K}^{-1}$ ) [28] is probably due to a high bulk density of the gel and loosely packed aerogel granule during measurement [30].
As compared to the density dependent thermal conductivity of typical silica aerogels prepared from TEOS, $18 \times$ $10^{-3} \mathrm{~W} \mathrm{~m}^{-1} \mathrm{~K}^{-1}$ at $0.2 \mathrm{~g} \mathrm{~cm}^{-3}$ [7], coal gangue derived silica aerogel displays higher thermal conductance, which is close to the reported waterglass-based aerogels [31].

\section{Conclusion}

We have developed a 3-step (acid purification, $\mathrm{Na}_{2} \mathrm{CO}_{3}$ activation, and acid leaching) route for effective extraction of silicon from a recycled coal gangue; an extraction yield of $99.5 \%$ w/w can be reached. After sol-gel transition, the wetgel was directly modified by TMCS/EtOH/n-heptane in single-step solvent exchange/silylation for fabricating mesoporous silica aerogel material. Typical hierarchical mesoporous structure was confirmed by SEM, TEM, and BET analysis, the pore size ranges from several $\mathrm{nm}$ to around $100 \mathrm{~nm}$, and most of the pores are in the mesoporous domain $(20-50 \mathrm{~nm})$. The aerogel density is $0.19 \mathrm{~g} \mathrm{~cm}^{-3}$ with high specific surface area $\left(690 \mathrm{~m}^{2} / \mathrm{g}\right)$ and high porosity $(>90 \%)$. The final aerogel material presents a good thermal insulation property of 26.5 $\times 10^{-3} \mathrm{~W} \mathrm{~m}^{-1} \mathrm{~K}^{-1}$, which was limited by in-house designed hot-wire transient method and may be improved in the future by applying an optimized granule packaging method.

This work demonstrates a feasible and economic ambient route to thermal insulating silica aerogels from the recycled solid waste, which offers insights into a cost reduction for industrial production of silica aerogels.

\section{Competing Interests}

The authors declare that they have no competing interests.

\section{Authors' Contributions}

Pinghua Zhu and Meng Zheng contributed equally to this work.

\section{Acknowledgments}

This work is financed by the National Natural Scientific Foundation of China (NSFC nos. 51308079, 51408073, and 51278073).

\section{References}

[1] M. A. Aegerter, N. Leventis, and M. M. Koebel, Aerogels Handbook, Springer, Berlin, Germany, 2011.

[2] S. D. Bhagat, Y.-H. Kim, Y.-S. Ahn, and J.-G. Yeo, "Rapid synthesis of water-glass based aerogels by in situ surface modification of the hydrogels," Applied Surface Science, vol. 253, no. 6, pp. 3231-3236, 2007.

[3] R. Baetens, B. P. Jelle, and A. Gustavsen, "Aerogel insulation for building applications: a state-of-the-art review," Energy and Buildings, vol. 43, no. 4, pp. 761-769, 2011.

[4] A. Soleimani Dorcheh and M. H. Abbasi, "Silica aerogel; synthesis, properties and characterization," Journal of Materials Processing Technology, vol. 199, no. 1, pp. 10-26, 2008. 
[5] S. S. Prakash, J. C. Brinker, A. J. Hurd, and S. M. Rao, "Silica aerogel films prepared at ambient pressure by using surface derivatization to induce reversible drying shrinkage," Nature, vol. 375, pp. 431-431, 1995.

[6] S. S. Kistler, "Coherent expanded aerogels and jellies," Nature, vol. 127, no. 3211, p. 741, 1931.

[7] A. Venkateswara Rao, E. Nilsen, and M.-A. Einarsrud, "Effect of precursors, methylation agents and solvents on the physicochemical properties of silica aerogels prepared by atmospheric pressure drying method," Journal of Non-Crystalline Solids, vol. 296, no. 3, pp. 165-171, 2001.

[8] A. Venkateswara Rao and S. D. Bhagat, "Synthesis and physical properties of TEOS-based silica aerogels prepared by two step (acid-base) sol-gel process," Solid State Sciences, vol. 6, no. 9, pp. 945-952, 2004.

[9] L. Wang and S. Zhao, "Synthesis and characteristics of mesoporous silica aerogels with one-step solvent exchange/surface modification," Journal Wuhan University of Technology, Materials Science Edition, vol. 24, no. 4, pp. 613-618, 2009.

[10] A. P. Rao, A. V. Rao, and J. L. Gurav, "Effect of protic solvents on the physical properties of the ambient pressure dried hydrophobic silica aerogels using sodium silicate precursor," Journal of Porous Materials, vol. 15, no. 5, pp. 507-512, 2008.

[11] F. Schwertfeger, D. Frank, and M. Schmidt, "Hydrophobic waterglass based aerogels without solvent exchange or supercritical drying," Journal of Non-Crystalline Solids, vol. 225, pp. 24-29, 1998.

[12] A. P. Rao, A. V. Rao, and G. M. Pajonk, "Hydrophobic and physical properties of the two step processed ambient pressure dried silica aerogels with various exchanging solvents," Journal of Sol-Gel Science and Technology, vol. 36, no. 3, pp. 285-292, 2005.

[13] C. Li, J. Wan, H. Sun, and L. Li, "Investigation on the activation of coal gangue by a new compound method," Journal of Hazardous Materials, vol. 179, no. 1-3, pp. 515-520, 2010.

[14] Y. Gao, H. Huang, W. Tang, X. Liu, X. Yang, and J. Zhang, "Preparation and characterization of a novel porous silicate material from coal gangue," Microporous and Mesoporous Materials, vol. 217, pp. 210-218, 2015.

[15] G. B. Stracher and T. P. Taylor, "Coal fires burning out of control around the world: thermodynamic recipe for environmental catastrophe," International Journal of Coal Geology, vol. 59, no. 1-2, pp. 7-17, 2004.

[16] T. Fu, Y. Wu, L. Ou, G. Yang, and T. Liang, "Effects of thin covers on the release of coal gangue contaminants," Energy Procedia A, vol. 16, pp. 327-333, 2012.

[17] L. Dong, Y. Li, J. Yan, and X. Q. Shu, "Efficient extraction of $\mathrm{SiO}_{2}$ and $\mathrm{AL}_{2} \mathrm{O}_{3}$ from coal Gangue by means of acidic leaching," Advanced Materials Research, vol. 878, pp. 149-156, 2014.

[18] C.-T. Hou, S.-Q. Wang, and X.-F. Xie, "Study on melting available silicone from coal gangue," Journal of Coal Science and Engineering, vol. 15, no. 4, pp. 426-429, 2009.

[19] J. M. Zhu, H. W. Cai, and N. N. Dang, "Study of synthesis of $\mathrm{SiO}_{2}$ aerogel from coal gangue at an ambient pressure," Advanced Materials Research, vol. 997, pp. 614-617, 2014.

[20] G. Xu, S. Li, X. Pan, G. Xu, J. Zhao, and B. Xi, "Study on preparation of amorphous nano-silica from coal gangue," in Proceedings of the International Conference on Materials for Renewable Energy \& Environment (ICMREE '11), pp. 1592-1594, Shanghai, China, May 2011.
[21] F. Q. Chen, F. Li, R. M. Chen, F. B. Xue, X. Duan, and Y. Sun, "Method for preparing silica through coal gangue aluminum extraction waste slag," China Patents, CN 103420386 A, 2013.

[22] R. Jia and X. Zhao, "Waterglass fabricated from coal gangue," Chinese Patents, Patent number, 2012.

[23] F. Shi and L.-J. Wang, "Rapid synthesis of silica aerogels via a new ambient pressure drying process," Journal of Dalian University of Technology, vol. 46, no. 2, pp. 241-245, 2006.

[24] M. Zheng, P. Zhu, J. Wu, H. Xu, and S. Zhao, "Synthesis and thermal insulation performance of silica aerogel from recycled coal gangue by means of ambient pressure drying," Journal of Wuhan University of Technology - Materials Science Edition, vol. 30, no. 5, pp. 908-913, 2015.

[25] Y. Guo, K. Yan, L. Cui, F. Cheng, and H. H. Lou, "Effect of $\mathrm{Na}_{2} \mathrm{CO}_{3}$ additive on the activation of coal gangue for alumina extraction," International Journal of Mineral Processing, vol. 131, pp. 51-57, 2014.

[26] A. Karaipekli, A. Sari, and K. Kaygusuz, “Thermal conductivity improvement of stearic acid using expanded graphite and carbon fiber for energy storage applications," Renewable Energy, vol. 32, no. 13, pp. 2201-2210, 2007.

[27] F. Frusteri, V. Leonardi, S. Vasta, and G. Restuccia, “Thermal conductivity measurement of a PCM based storage system containing carbon fibers," Applied Thermal Engineering, vol. 25, no. 11-12, pp. 1623-1633, 2005.

[28] S. Zhao, B. Jiang, T. Maeder et al., "Dimensional and structural control of silica aerogel membranes for miniaturized motionless gas pumps," ACS Applied Materials \& Interfaces, vol. 7, no. 33, pp. 18803-18814, 2015.

[29] L. Wang and S. Zhao, "Synthesis and characteristics of mesoporous silica aerogels with one-step solvent exchange/surface modification," Journal of Wuhan University of TechnologyMaterials Science Edition, vol. 24, no. 4, pp. 613-618, 2009.

[30] A. Neugebauer, K. Chen, A. Tang, A. Allgeier, L. R. Glicksman, and L. J. Gibson, "Thermal conductivity and characterization of compacted, granular silica aerogel," Energy and Buildings, vol. 79, pp. 47-57, 2014.

[31] L.-J. Wang, S.-Y. Zhao, and M. Yang, "Structural characteristics and thermal conductivity of ambient pressure dried silica aerogels with one-step solvent exchange/surface modification," Materials Chemistry and Physics, vol. 113, no. 1, pp. 485-490, 2009. 

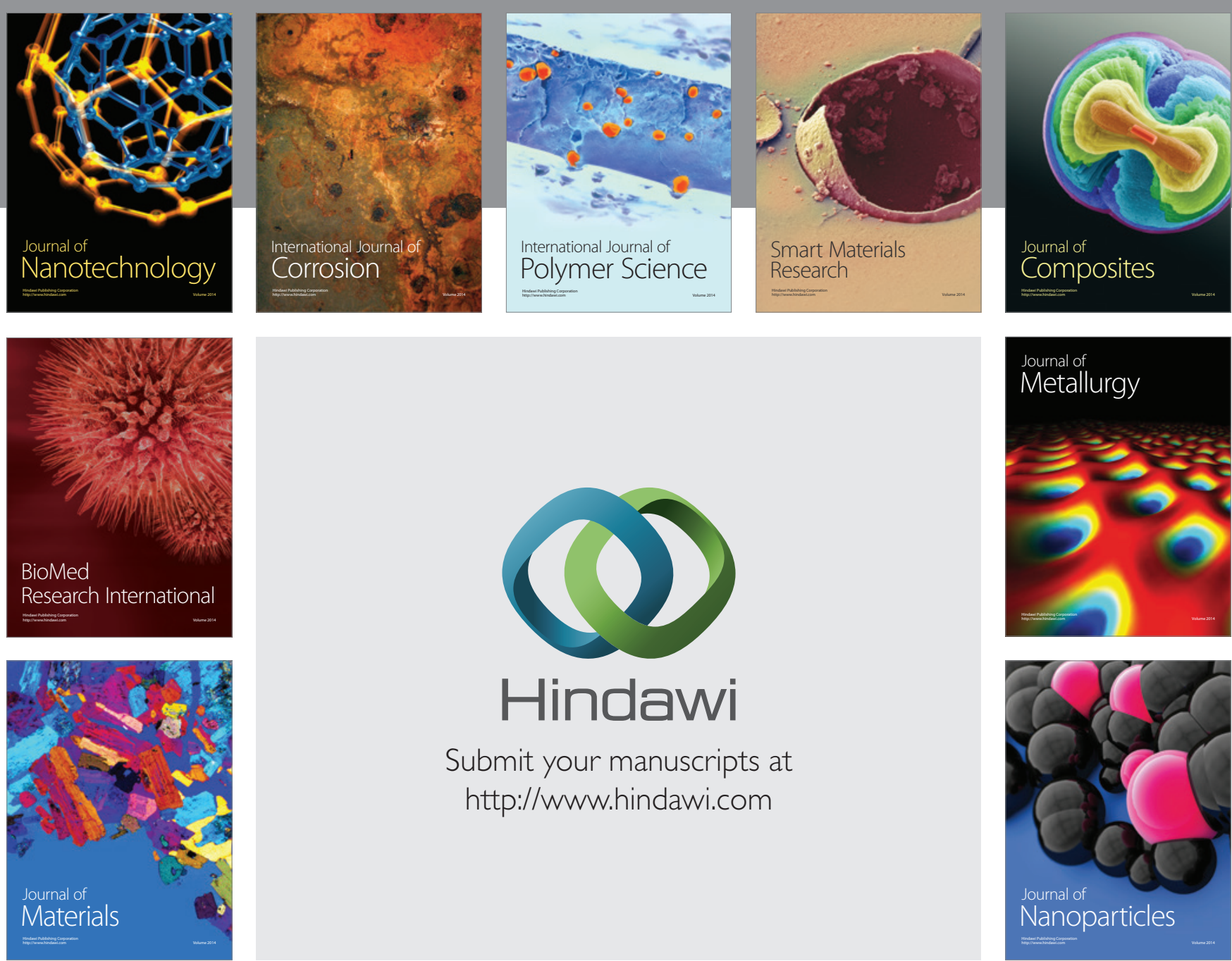

\section{Hindawi}

Submit your manuscripts at

http://www.hindawi.com

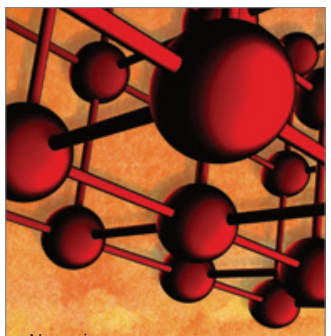

Materials Science and Engineering

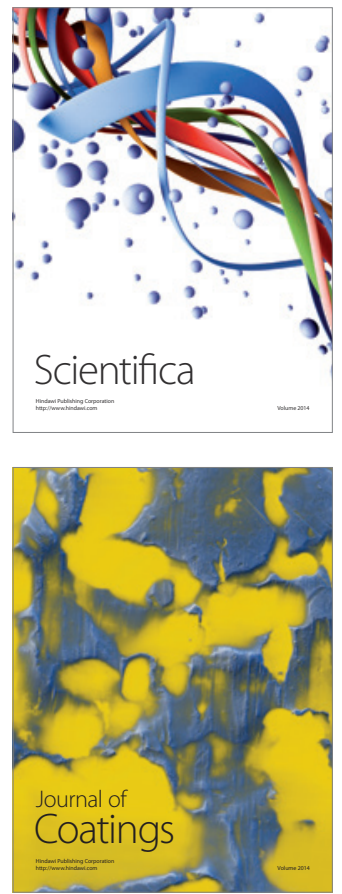
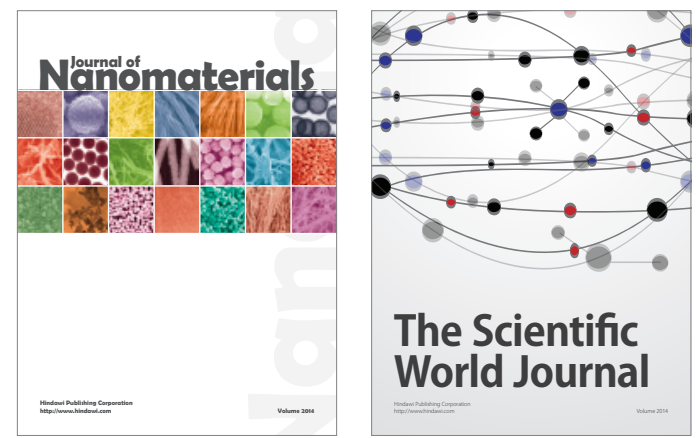

The Scientific World Journal
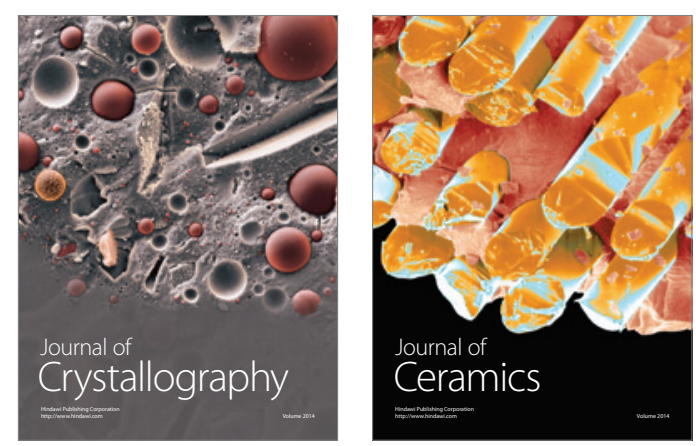
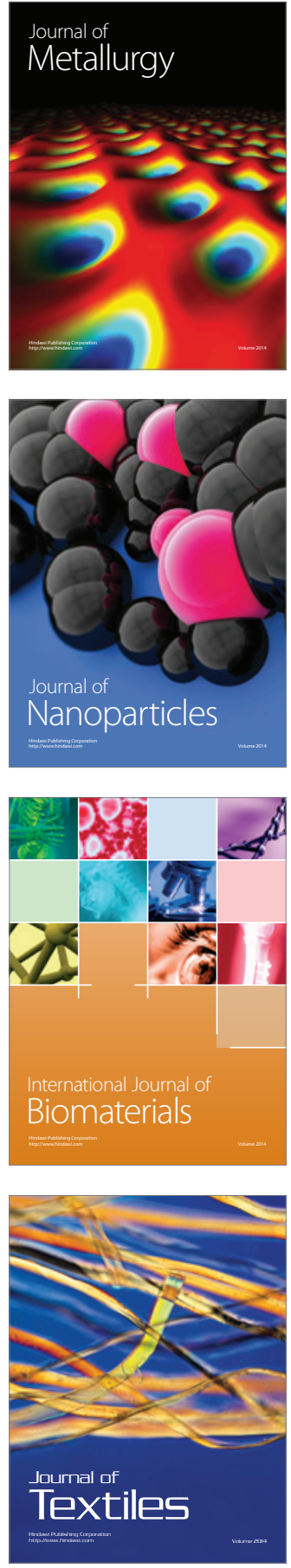